\title{
Mechanical Performances and Structure Optimization of H-shaped Steel and Cement- Soil Wall
}

\author{
Jianhui Yang ${ }^{1}$, Yekun Jin ${ }^{1}$, Jialin Wei ${ }^{2}$ and Chunliu $\mathbf{L i}^{3 *}$

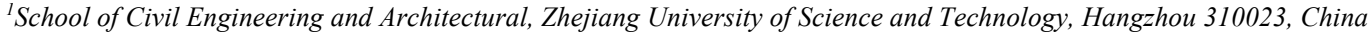 \\ ${ }^{2}$ International Joint Research Laboratory of Henan Province for Underground Space Development and Disaster Prevention, \\ Henan Polytechnic University, Jiaozuo 454003, China \\ ${ }^{3}$ Institute of Urban Construction, Hebei Normal University of Science \& Technology, Qinhuangdao 066004, China
}

Received 2 September 2019; Accepted 29 November 2019

\begin{abstract}
The H-shaped steel spacing and cement content are the key parameters of TRD (Trench cutting Re-mixing Deep wall), which directly affects the stress and displacement of the wall. To ensure the stability of the foundation pit, it is of great practical significance to optimize the steel spacing and cement content. Taking the urban utility tunnel in Hangzhou as the engineering background, the triaxial tests of cement-soil were conducted to study the influence of cement content on the strength of the cement-soil. The finite element model was established to analyze the deformation, stress distribution of cement-soil, and the spacing of H-shaped steel. Results show that the unconfined compressive strength and elastic modulus of cemented-soil increase linearly with the increase of the cement content in the range of $10 \%-25 \%$. The tensile stress formed on the side of the foundation pit leads to the cement-soil damage, where there is the maximum horizontal displacement. According to the relationship between the cement content and the maximum H-shaped steel spacing, the optimized steel spacing and the cement content can be determined. The obtained conclusions can provide a reference for the similar engineering.
\end{abstract}

Keywords: Foundation pit, retaining structure, cement-soil , H-shaped steel spacing

\section{Introduction}

The TRD (Trench cutting Re-mixing Deep wall) method was originally derived from Japan [1]. Compared with the traditional SMW (Soil Mixing Wall) method, it has many advantages, such as high stability, strong applicability, good wall quality, and good water insulation effect [2-4]. In recent years, with the continuous development of urban underground space in China, TRD construction method was widely used in various foundation pit engineering.

In the retaining structure of $\mathrm{H}$-shaped steel and cementsoil wall by using TRD method, the soil load is jointly shared by the $\mathrm{H}$-shaped steel and the cement-soil, causing bending deformation of the H-shaped steel and cement-soil and even causing the cement-soil to be destroyed, which often poses a security threat to the foundation pit excavation.

Therefore, to ensure the stability of the foundation pit engineering, it is key to optimize the steel spacing and cement content of the retaining structure of $\mathrm{H}$-shaped steel and cement-soil wall, which has important reference significance for the design and construction of the similar engineering.

\section{State of the art}

For the mechanism analysis of the TRD method, Tan et al. analyzed the interaction mechanism of the steel wall and cement-soil and considered that the average staggered shear

*E-mail address: Iclce_010@163.com

ISSN: 1791-2377 @ 2019 School of Science, IHU. All rights reserved.

doi:10.25103/jestr.126.24 stress was the main factor causing the destruction of the cement-soil [5]. Zheng et al. found that the cement-soil on the location of bending failure was severely cracked and the bond was completely destroyed between the H-shaped steel and the cement-soil during the loading tests [6]. Xie et al. believed that with the increase of the bending moment of the mixing wall, the tensile strength of cement-soil reached the tensile strength and began to crack during the loading test of steel-cement composite beams [7]. Kim et al. evaluated the applicability of an eco-friendly porous media binder (CMDSOIL) for the deep cement-soil mixing using desulfurized ash left behind in a power plant by waste [8].

For the properties of cement-soil, a large number of tests have been carried out and a lot of test results have been achieved [9-12], which shows that under laboratory conditions the unconfined compressive strength of cementsoil increases with the increase of cement content and curing age. For examples, Ma et al. found that the tensile strength of cement-soil is equal to $15 \%-25 \%$ of the $28 \mathrm{~d}$ unconfined compressive strength; the standard value of the shear strength of cement-soil is equal to $1 / 3$ of that of the mixing wall by using the TRD excavation method [13-14]. Based on the above mentioned literatures, we can find that there are many researches on the failure mechanism of the steel and cement-soil wall. But there are few studies reported on the reasonable steel spacing and cement content, and the relationship between the cement content and the maximum $\mathrm{H}-$ shaped steel spacing.

The TRD construction method was adopted in the urban utility tunnel in Hangzhou, China, and its retaining structure was the H-shaped steel and cement-soil wall. The ground 
settlement, horizontal displacement and support axial force were monitored during the construction. All the displacements and axial forces were much smaller than the alarm values, which indicating that the design of the mixing wall was conservative, and the retaining structure can be optimized by increasing the steel spacing and reducing the cement content. So, to reduce the construction cost under the premise of ensuring the stability of the foundation pit, it is necessary to study the mechanical performances of TRD method to propose the reasonable steel spacing and cement content.

The organizational structure of the rest of this study is as follows: Section 3 introduces the general situation of the project and describes the research mothods. Section 4 gives the analysis and discussions of test results. Section 5 summarizes the study and draws relevant conclusions.

\section{Methodology}

\subsection{Enginering background}

The urban utility tunnel in Hangzhou was constructed by open cut method, its total length is $6083.84 \mathrm{~m}$, but the test part is only $200 \mathrm{~m}$ long. As shown in Fig. 1, the width of the foundation pit is $9.75-12.05 \mathrm{~m}$, and which excavation depth is $7-10 \mathrm{~m}$. The retaining structure of the foundation pit is $850 \mathrm{~mm}$ thick of the H-shaped steel and cement-soil wall by using TRD method, inside with H-shaped steel (height $\times$ width $\times$ web thickness $\times$ flange thickness) $700 \mathrm{~mm} \times 300$ $\mathrm{mm} \times 13 \mathrm{~mm} \times 24 \mathrm{~mm}$, and the H-shaped steel spacing is $0.90 \mathrm{~m}$ and the effective length is $18 \mathrm{~m}$. Two inner supports are set, and the first support is reinforced concrete piles with a section of diameter $800 \mathrm{~mm}$ and spacing $800 \mathrm{~mm}$, and with a spacing of $7 \mathrm{~m}$, and the second support is the steel pipe diameter $609 \mathrm{~mm}$, thickness $16 \mathrm{~mm}$ with a spacing of 4.50 $\mathrm{m}$.

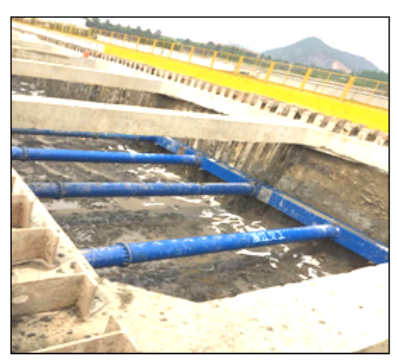

(a) Top view

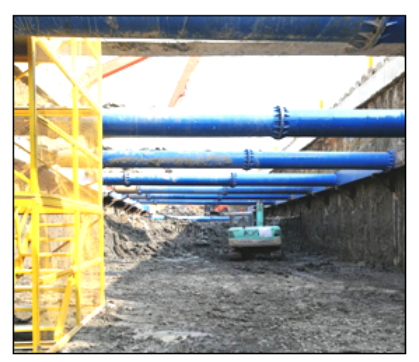

(b) Bottom view
Fig. 1. The foundation pit excavation

According to the engineering geological exploration report (see Table 1), the site soil of this project is soft soil, class III. Among the soft soils, the fill soil has large deformation under loading, easy to affect the stability of the retaining structure. The silt soil is low strength and high compressibility. The water level at the construction site is relatively high, the water depth is $0.80-3.50 \mathrm{~m}$ below the ground, and the confined water level below the ground is buried at $2.49 \mathrm{~m}$.

\subsection{On-site coring and cement-soil test}

The GXY-IA drilling rig was used for on-site coring of this project, and the core sample diameter is $90 \mathrm{~mm}$. The core samples of cement-soil were numbered and tested in the laboratory for unconfined compressive strength. The average value of the unconfined compressive strength was $1.13 \mathrm{MPa}$, which was greater than the design strength of $1.00 \mathrm{MPa}$, which met the design requirements of the mixing wall.
The test soil was taken from the site of the project. Before the test the soil sample was air-dried, crushed, and passed through a $1.00 \mathrm{~mm}$ sieve. The P.O. 42.5 ordinary Portland cement was selected, and the adding amount of $\alpha_{c}$ was $10 \%, 15 \%, 20 \%, 25 \%$ of dry weight of the undisturbed soil. The standard sample was a diameter of $3.91 \mathrm{~cm}$ and a height of $8.00 \mathrm{~cm}$, which was made from the mixed soil sample. The unconfined compressive strength and consolidated undrained shear tests were carried out by using stress controlled triaxial testing system (TKA-TTS-1S).

The samples were cured under standard curing conditions for $7 \mathrm{~d}, 14 \mathrm{~d}$, and $28 \mathrm{~d}$ in the unconfined compressive strength test, and the loading rate was controlled at $0.08 \% / \mathrm{min}$. The samples used in the consolidated undrained shear test were evacuated for $24 \mathrm{~h}$ in a vacuum saturator, and then were cured in sufficient water for $7 \mathrm{~d}$ under saturated conditions. These tests were carried out under laboratory confining pressure of $80 \mathrm{kPa}, 160 \mathrm{kPa}$, $240 \mathrm{kPa}$, and the loading rate was controlled at $0.08 \% / \mathrm{min}$.

\subsection{Finite element analysis}

\subsubsection{Computational model}

Based on the actual project, the three-dimension computational model of the foundation pit excavation was established by ABAQUS software. The excavation depth is $10 \mathrm{~m}$, the excavation width is $10 \mathrm{~m}$, and the longitudinal length is $10 \mathrm{~m}$. The model monitoring points were located in the middle of the longitudinal direction, which were consistent with the arrangement of the field measurement points. Considering the boundary effect and the influence range of the foundation pit, the total width of the model is $51.7 \mathrm{~m}$ and the height is $30 \mathrm{~m}$. The three-dimension model was shown in Fig. 2, and the $x$-axis of the model was along the longitudinal direction of the mixing wall.

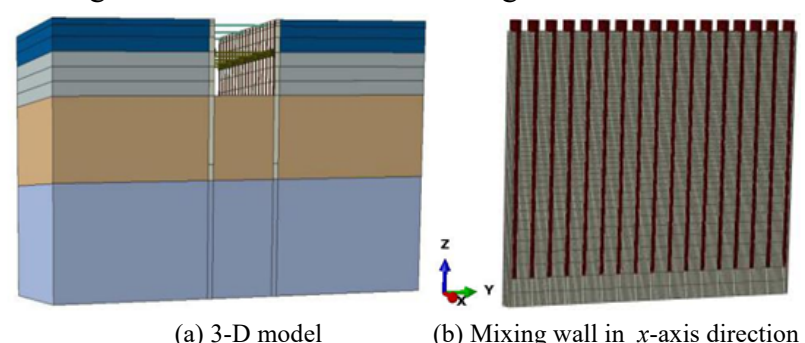

Fig. 2. Numerical model and mixing wall

Considering the initial stress field, the model was calculated in eight steps, and its construction process was simulated such as the mixing wall construction, the steel inserting, the reinforced concrete support and the steel support. The foundation pit excavation was carried out in 6 steps. The first two excavation steps were $0.80 \mathrm{~m}$ and $1.20 \mathrm{~m}$ respectively, and then each excavation step was $2.0 \mathrm{~m}$.

According to equivalent bending stiffness rule, the cement-soil in the flange area and the $\mathrm{H}$-shaped steel were equivalent to the same thickness as the wall to simplify the calculation, and the elastic modulus of equivalent material is $1.22 \times 10^{3} \mathrm{MPa}$. The model thickness of the mixing wall was consistent with that of the site, the steel spacing is $0.90 \mathrm{~m}$. 17 steel sections were inserted into both sides of the foundation wall separately, as shown in Fig. 2(b). The MohrCoulomb constitutive model was adopted and the parameters of the soil and the cement-soil were shown in Table 1. The crown beam, the steel cofferdam, the reinforced concrete support and the steel support were set to be linear elastic, and the elastic modulus of the crown beam and the concrete 
support is $3.0 \times 10^{4} \mathrm{MPa}$, and the elastic modulus of the steel cofferdam and the steel support is $2.1 \times 10^{5} \mathrm{MPa}$.

Table 1. Materials parameters of the model.

\begin{tabular}{|c|c|c|c|c|c|c|}
\hline \multicolumn{2}{|c|}{ Soil layer } & $\begin{array}{r}\text { Density } \\
\left(\mathrm{g} / \mathrm{cm}^{3}\right)\end{array}$ & $\begin{array}{c}\text { Elasticity } \\
\text { Modulus } \\
\text { (MPa) }\end{array}$ & $\begin{array}{l}\text { Poisson's } \\
\text { ratio }\end{array}$ & $\begin{array}{c}\text { Cohesive } \\
\text { strength } \\
\text { (kPa) }\end{array}$ & $\begin{array}{l}\text { Internal } \\
\text { friction } \\
\text { angle }\left(^{\circ}\right)\end{array}$ \\
\hline \multicolumn{2}{|c|}{$\begin{array}{l}\text { Miscellaneous } \\
\text { fill }\end{array}$} & 1.80 & 28 & 0.32 & 10.0 & 15 \\
\hline \multicolumn{2}{|c|}{ Silty clay } & 1.90 & 34 & 0.30 & 15.7 & 20 \\
\hline \multicolumn{2}{|c|}{ Clay } & 2.05 & 32 & 0.31 & 11.8 & 20 \\
\hline \multicolumn{2}{|c|}{ Sandy clay } & 1.95 & 32.5 & 0.31 & 40 & 30 \\
\hline \multicolumn{2}{|c|}{ Round gravel } & 2.00 & 110.6 & 0.2 & 1.0 & 35 \\
\hline \multicolumn{2}{|c|}{$\begin{array}{c}\text { Weathered silty } \\
\text { mudstone }\end{array}$} & 1.95 & 32.1 & 0.25 & 46.5 & 18 \\
\hline Cement & 10 & & 35.4 & 0.32 & 97.9 & 31 \\
\hline content & 15 & & 62.9 & 0.29 & 210.2 & 35 \\
\hline $\begin{array}{c}\text { of } \\
\text { cement- }\end{array}$ & 20 & 2.10 & 90.6 & 0.26 & 224.6 & 39 \\
\hline $\begin{array}{l}\text { soil } \\
(\%)\end{array}$ & 25 & & 113.6 & 0.25 & 409.6 & 40 \\
\hline
\end{tabular}

\subsubsection{Simulation schemes}

As shown in Table 2, considering the variation of cement content and $\mathrm{H}$-shaped steel spacing of the mixing wall, different numerical models were established. The No. 2.4 model was consistent with that of the site, the steel spacing was $0.90 \mathrm{~m}$ and the cement content was $25 \%$.

Table 2. Numerical simulation scheme.

\begin{tabular}{c|c|c}
\hline Model name & $\begin{array}{c}\text { H-shaped steel } \\
\text { spacing }(\mathbf{m})\end{array}$ & $\begin{array}{c}\text { Cement content } \\
(\mathbf{\%})\end{array}$ \\
\hline No. 1.1 & & 10 \\
No. 1.2 & & 15 \\
No. 1.3 & 0.6 & 20 \\
No. 1.4 & & 25 \\
No. 2.1 & & 10 \\
No. 2.2 & & 15 \\
No. 2.3 & 0.9 & 20 \\
No. 2.4 & & 25 \\
No. 3.1 & 1.2 & 20 \\
No. 3.2 & & 25 \\
No. 4.1 & 1.5 & 25 \\
\hline
\end{tabular}

\section{Results and discussion}

\subsection{The monitored results analysis}

For this project, the cement content of mixing wall is $25 \%$, and the steel spacing is $0.90 \mathrm{~m}$. The measured maximum displacement rate and the maximum cumulative displacement are shown in Table 3.

Table 3. The measured maximum displacement rate and maximum cumulative displacement.

\begin{tabular}{c|c|c|c|c}
\hline \multirow{2}{*}{ Name } & \multicolumn{2}{|c|}{$\begin{array}{c}\text { Maximum displacement } \\
\text { rate (mm/d) }\end{array}$} & \multicolumn{2}{c}{$\begin{array}{c}\text { Maximum cumulative } \\
\text { displacement (mm) }\end{array}$} \\
\cline { 2 - 5 } & $\begin{array}{c}\text { Monitoring } \\
\text { value }\end{array}$ & $\begin{array}{c}\text { Alarm } \\
\text { value }\end{array}$ & $\begin{array}{c}\text { Monitoring } \\
\text { value }\end{array}$ & $\begin{array}{c}\text { Alarm } \\
\text { value }\end{array}$ \\
\hline $\begin{array}{c}\text { Ground } \\
\text { settlement }\end{array}$ & -1.10 & \pm 3 & -17.51 & \pm 40 \\
\hline $\begin{array}{c}\text { Settlement of th } \\
\text { wall top }\end{array}$ & -1.31 & \pm 3 & -6.40 & \pm 20 \\
\hline $\begin{array}{c}\text { Horizontal } \\
\text { displacement } \\
\text { of retaining } \\
\text { structure }\end{array}$ & 1.40 & \pm 3 & 8.90 & \pm 30 \\
\hline
\end{tabular}

It can be seen in Table 3 that the maximum displacement rate and the cumulative displacement is $37 \%-47 \%$ and $30 \%$ $44 \%$ of the alarm values, respectively. There is a large difference between the monitored and the alarm values. The horizontal support axial force was monitored and its maximum force of the first support is $1701 \mathrm{kN}$, which is less than the alarm value of $4760 \mathrm{kN}$. The maximum axial force of the second support is $1302 \mathrm{kN}$, which is less than the alarm value of $3500 \mathrm{kN}$. From the displacement and axial force monitored resluts, it can be seen that the stiffness and strength of the mixing wall remain much, and there is still room for optimization in terms of steel spacing and cement content.

\subsection{Properties of cement-soil}

As shown in Fig. 3(a), with the cement content and curing age increasing, the unconfined compressive strength increases accordingly. The unconfined compressive strength with $25 \%$ cement content at $28 \mathrm{~d}$ reached $5.19 \mathrm{MPa}$, and that of the site coring sample was $1.13 \mathrm{MPa}$. It can be seen that the strength measured in the laboratory is much higher than that of the site coring sample. The reason is that the undisturbed soil and the cement slurry are only stirred in return cutting process by the TRD pile driver, and the cement-soil mixing is insufficient, so that value is far less than the mixing uniformity under the laboratory conditions, the reduction factor of 0.22 can be determined through the on-site coring sample strength dividing by the strength of the laboratory sample. According to this coefficient, the shear and tensile strength values of the cement-soil in the project with different cement content can be approximately obtained.

According to the undrained shear test results under different confining pressures, the cohesion and internal friction angle of the cement-soil can be obtained. As shown in Fig. 3(b), it can be seen that the cohesion and internal friction angle increase with cement content increasing, which is consistent with others research [15-16].

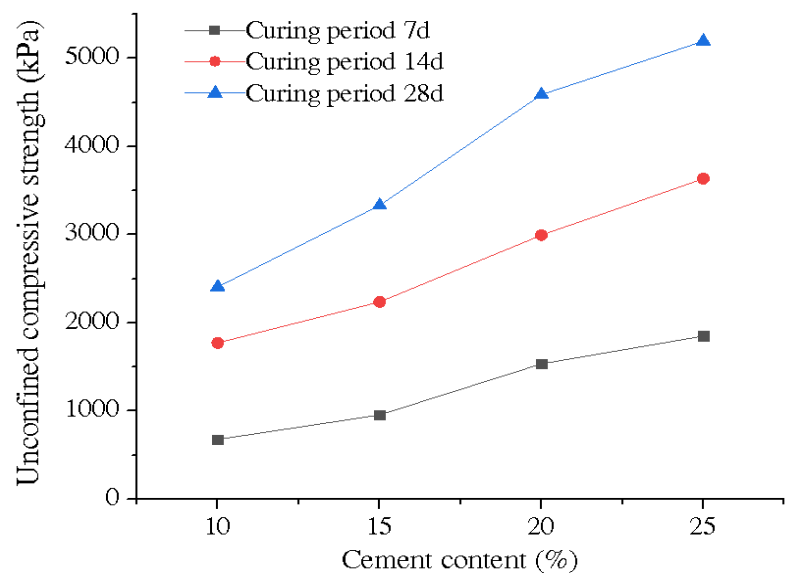

(a) Relationship curves between unconfined compressive strength and cement content.

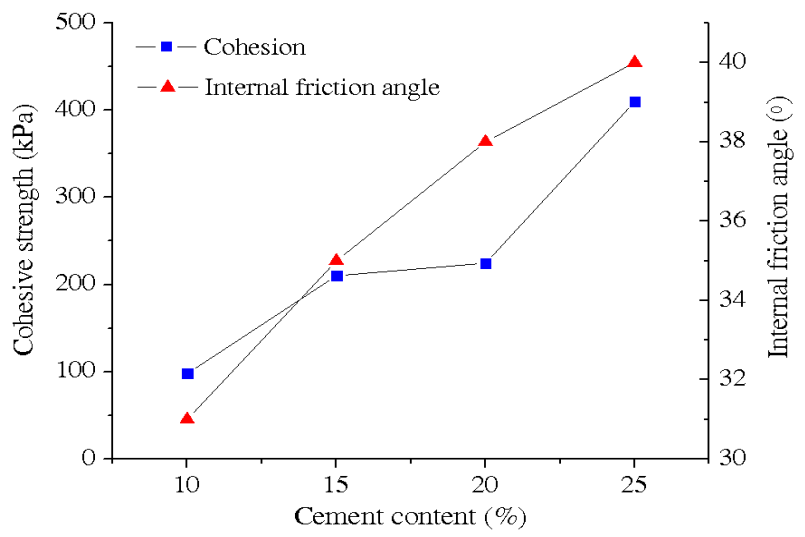

(b) Relationship curves among cohesion, internal friction angle and cement content. 


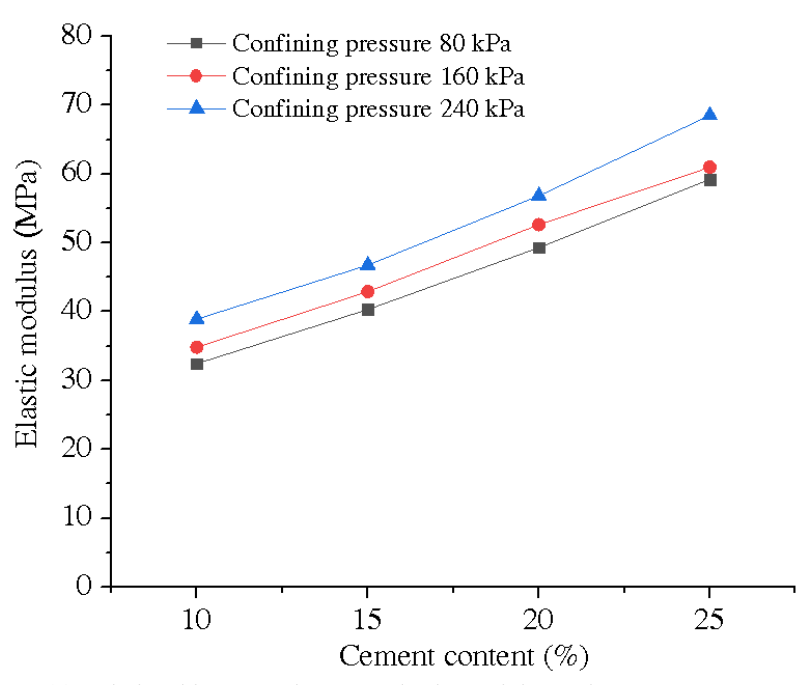

(c) Relationship curves between elastic modulus and cement content. Fig. 3. The properties of the cement-soil.

According to the consolidation and undrained shear test results, the relationship between the elastic modulus and the cement content is shown in Fig. 3(c). It can be seen that the elastic modulus is basically a linear increase with the increase of cement content in 10\%-25\% range. The elastic modulus increases accordingly as the confining pressure increases, consistent with other studies [17-18].

\subsection{Deformation characteristics analysis}

Under the earth pressure and lateral constrain, the H-shaped steel and the cement-soil of mixing wall vertically bent and deformed to the foundation pit. The cement-soil was in a bending state in the vertical and horizontal axis direction, as shown in Fig. 4. The calculating displacement is a superposition of both direction displacements.

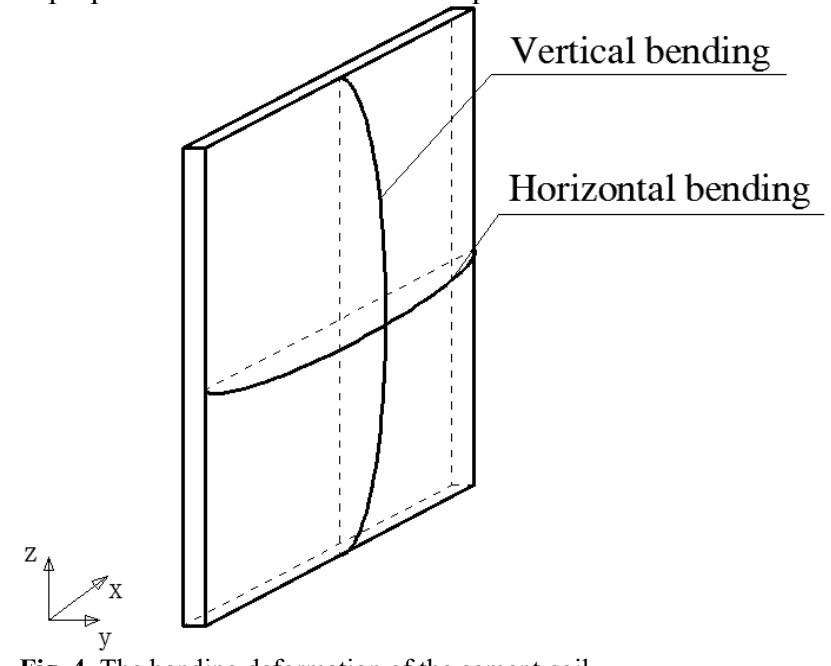

Fig. 4. The bending deformation of the cement-soil.

During the process of the foundation pit excavation, the inclinometer was placed on the facing surface side of the $\mathrm{H}$ shaped steel (located in the middle of the longitudinal direction of the model), and the horizontal displacement of the H-shaped steel was monitored. The monitored horizontal displacement along the pit depth direction and the numerical simulation results of the model No. 2.4 correspondingly are shown in Fig. 5.

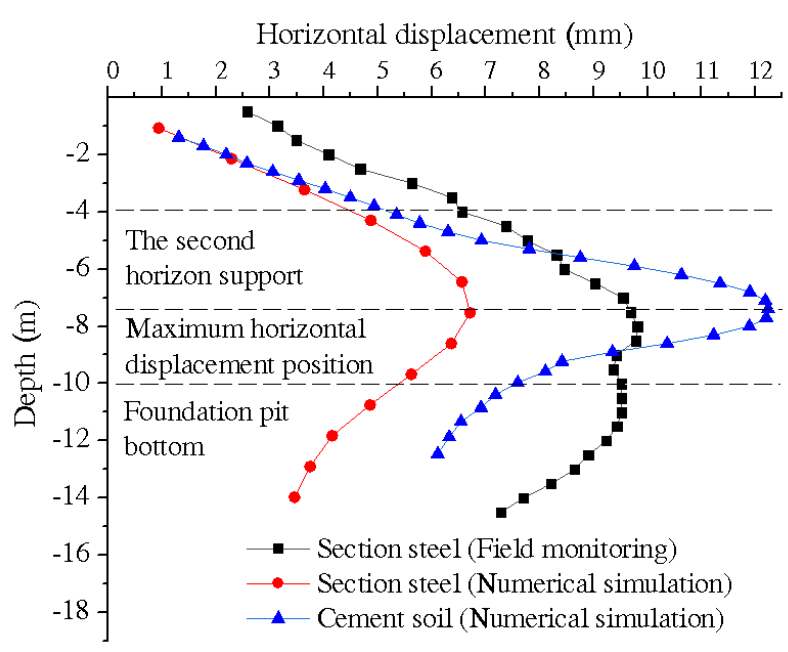

Fig. 5. Horizontal displacement distribution of the H-shaped steel and cement-soil.

As seen from Fig. 5, the horizontal displacements of the field and simulated model changed with the depth showing as "bull belly shape", and the both maximum horizontal displacement occurred at $1 / 3$ excavation depth from the pit bottom, which is located the position of $-6.77 \mathrm{~m}$. The second horizontal support was arranged at the position of $-4.00 \mathrm{~m}$, and the position below $-10 \mathrm{~m}$ was the solid soil, and the middle horizontal displacement between the two positions was the largest due to the constraint of the soil and horizontal support. The field maximum horizontal displacement was measured $9.81 \mathrm{~mm}$, and that of the the numerical simulation was $6.71 \mathrm{~mm}$, and the difference was $3.10 \mathrm{~mm}$, which is related to the binding between the enclosure and the bottom soil constrained the bottom horizontal displacement in the numerical model.

The cement-soil displacement distribution in Fig. 5 was also showed as "bull belly shape", and the position of the maximum horizontal displacement basically was the same as that of the H-shaped steel. There is a horizontal displacement difference between the cement-soil and $\mathrm{H}$ shaped steel. And the horizontal displacement difference gradually increased from the second steel support position ($4.0 \mathrm{~m}$ ) to the pit bottom, reached the maximum value and then gradually decreased. The maximum horizontal displacement occurred in the middle, and the horizontal displacement distribution curvature at the position was also the largest.

\subsection{Structure stress characteristics}

In the vertical plane of $y o z$, due to the cement-soil bending deformation, the tensile stress S33 was generated in the cement-soil. As sghown in Fig. 6, the calculation result of the model No. 2.4 showed that the maximum value of S33 was located at $1 / 3$ of the excavation depth from the pit bottom, which was consistent with the horizontal displacement maximum position and the deflection curve curvature maximum in Fig. 5.

The tensile stress at the maximum position of S33 in model No. 2.4 was shown in Fig. 7. The cement-soil on the pit side was pulled and the other side was pressed, which conformed to the bending stress deformation rule. The maximum value of S33 was $143 \mathrm{kPa}$, which was less than $170 \mathrm{kPa}$ of the tensile strength of the cement-soil with the cement content less than $25 \%$. 


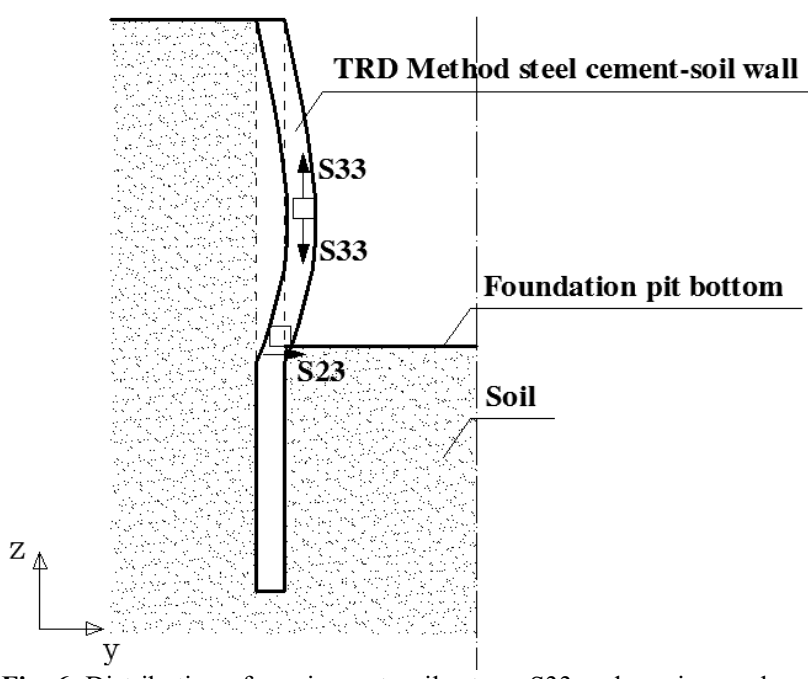

Fig. 6. Distribution of maximum tensile stress S33 and maximum shear stress S23 of cement-soil.

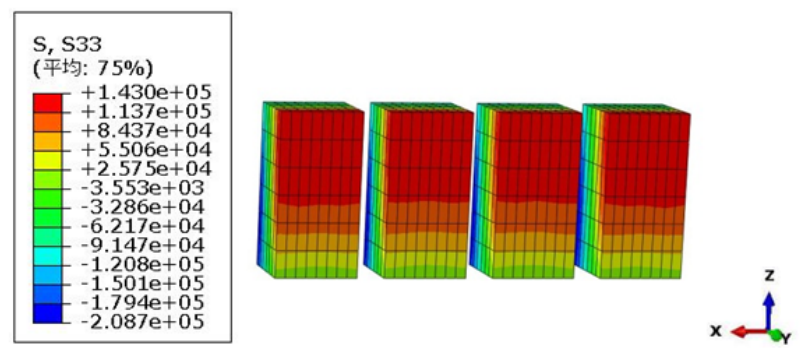

(a) Maximum tensile stress S33

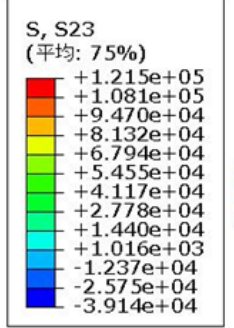

(b) Maximum shear stress S23

Fig. 7. The maximum tensile stress S33 and maximum shear stress S23 of cement-soil

In the vertical plane of $x o z$, due to the horizontal bending deformation of the cement-soil between the H-shaped, the tensile stress S11 of the cement-soil occurred on the pit side. As shown in Fig. 8, the calculation result of the model No. 2.4 showed that the maximum value of $\mathrm{S} 11$ of the cementsoil between the two steel bars was located at $1 / 3$ of the excavation depth from the pit bottom, where the horizontal displacement difference between the H-shaped steel and the cement-soil was largest (Fig. 4), where the horizontal bending deformation curvature also was maximum in Fig. 5.
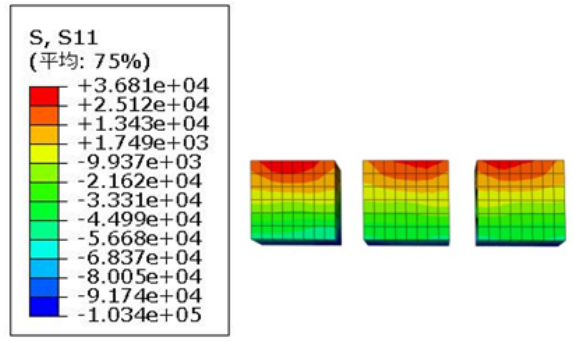

(a) Maximum tensile stress $\mathrm{S} 11$
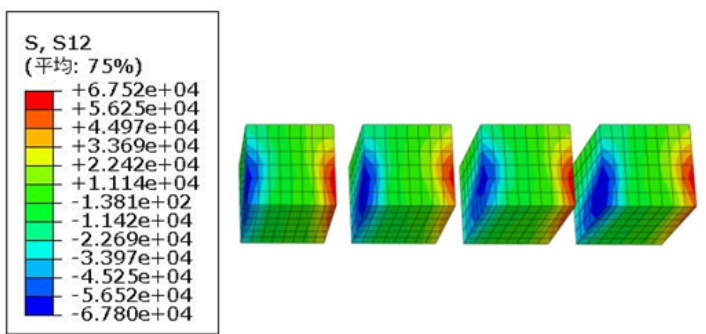

(b) Maximum shear stress S12

Fig. 8. The maximum tensile stress $\mathrm{S} 11$ and maximum shear stress S12 stress of cement-soil

\subsection{Retaining structures characteristics}

In models No. 2.1 to 2.4 , the steel spacing was $0.90 \mathrm{~m}$, the cement content was $10 \%-25 \%$, the displacement reduced slightly with the increase of cement content, and the change was not large. The reason was that the stiffness of H-shaped steel was far greater than that of the cement-soil, and the $\mathrm{H}$ shaped steel was the main bending member, and the cement content has little effect on the overall bending stiffness.

As shown in Fig. 9(a), the stress S11 value is small, the S33 stress value is large, and the S33 has a greater influence on the mixing wall stability, and S33 increases with the cement content increasing. When the cement content $\alpha_{c}$ is less than $18.62 \%$, the mixing wall cement-soil will be damaged by tension. Therefore, in order to ensure that the mixing wall safety, the cement content must be greater than $18.62 \%$ with $0.90 \mathrm{~m}$ steel spacing.

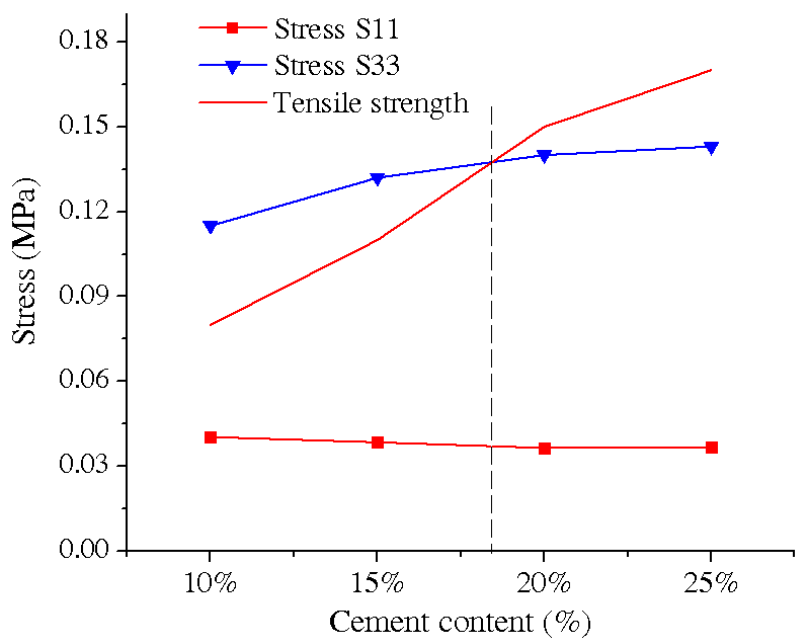

(a) Relationship among S11, S33 stress and cement content

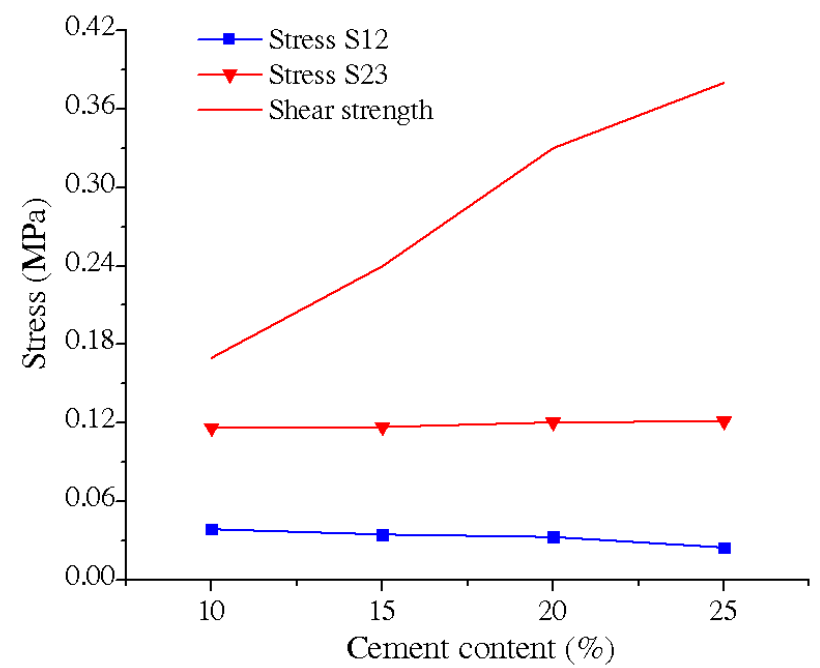

(b) Relationship among S12, S23 stress and cement content 
Fig. 9. The relationship between maximum stress of cement-soil and cement content.

As shown in Fig. 9(b), the stress S12 and S23 are smaller than the shear strength of cement-soil, and the cement content variation has little effect on the cement-soil shear stress between H-shaped steel bars. Since the maximum horizontal tensile stress $\mathrm{S} 11$ and the maximum shear stress S12, S23 have little effect on the stability of cement-soil, so the vertical tensile stress of S33 was the failure stress of the mixing wall.

The cement content of the models No.1.1, 2.1, 3.1, and 4.1, was $25 \%$, but the steel spacing was $0.60 \mathrm{~m}, 0.90 \mathrm{~m}, 1.20$ $\mathrm{m}, 1.50 \mathrm{~m}$, respectively. As shown in Fig. 10, the displacement increases with the steel spacing increasing, and in the range of $1.20-1.50 \mathrm{~m}$ the variation rate is the fastest. Compared with the cement content, the variation of the steel spacing has a more obvious effect on the stiffness of the mixing wall.

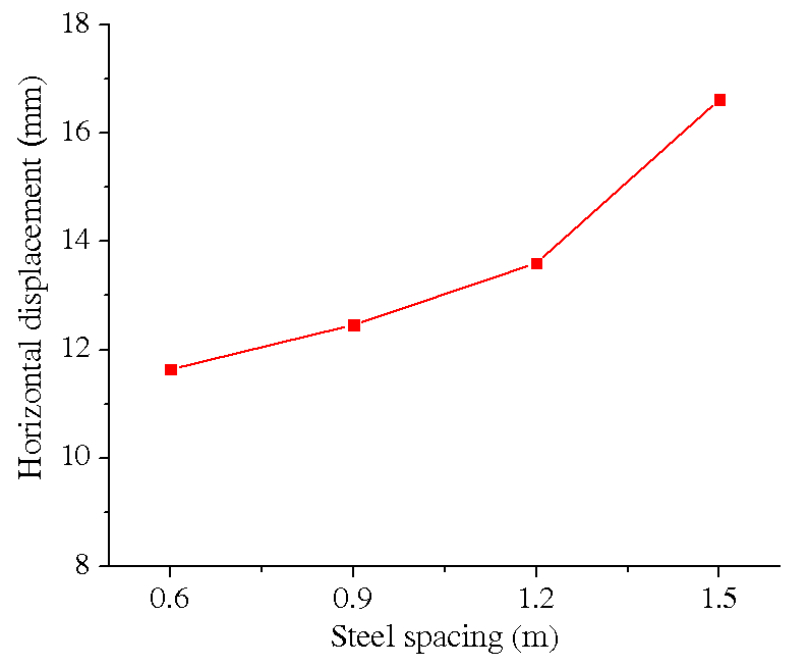

Fig. 10. Relationship between the maximum horizontal displacement of mixing wall and steel spacing

As shown in Fig. 11. the tensile stress S33 of the cement-soil increases with the steel spacing increasing. When the steel spacing is greater than $1.13 \mathrm{~m}$, the tensile strength of S33 exceeds the tensile strength, and the cementsoil of the mixing wall is damaged by tension. Therefore, when the cement content of the mixing wall is $25 \%$, the steel spacing should not be greater than $1.13 \mathrm{~m}$.

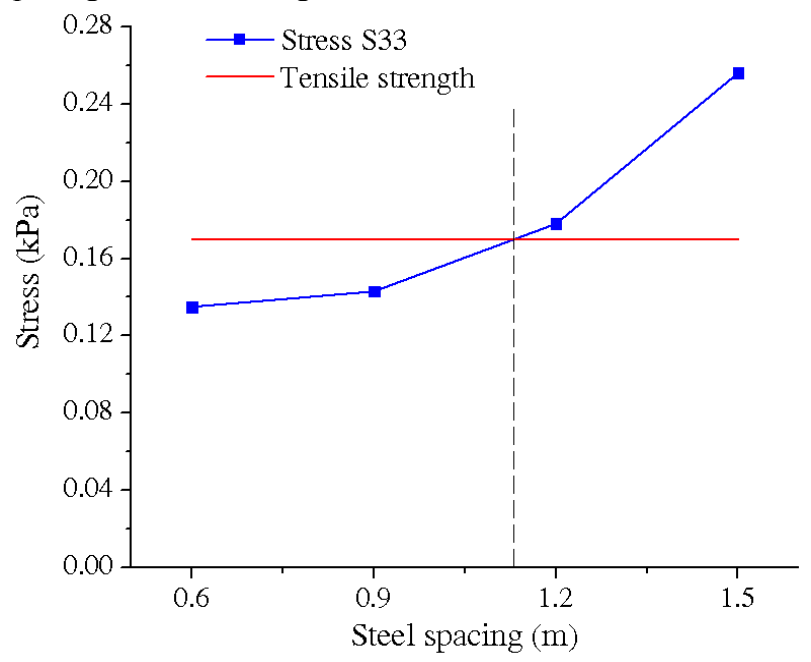

Fig. 11. Relationship between maximum stress of cement-soil and spacing of H-shaped steel.

\subsection{Mixing wall safety analysis}

According to Fig. 9(a), the minimum cement content corresponding to the $0.90 \mathrm{~m}$ steel spacing can be obtained, and according to Fig. 11, the maximum steel spacing corresponding to the cement content of $25 \%$ can be obtained. Similarly, the cement content corresponding to the $0.60 \mathrm{~m}$ steel spacing and the maximum steel spacing corresponding to $15 \%$ and $20 \%$ cement content can be obtained in Table 4.

As shown in Fig. 12. the steel spacing increases accordingly as the cement content increasing. Furthermore, the strength of the cement-soil is required to be larger as the steel spacing increases. The reason is that when the steel spacing increases, the $\mathrm{H}$-shaped steel restraining to the cement-soil will weaken relatively, and the cement-soil stiffness should be increased in order to ensure the mixing wall safety.

Table. 4. Comparison table of minimum cement content and maximum H-shaped steel spacing

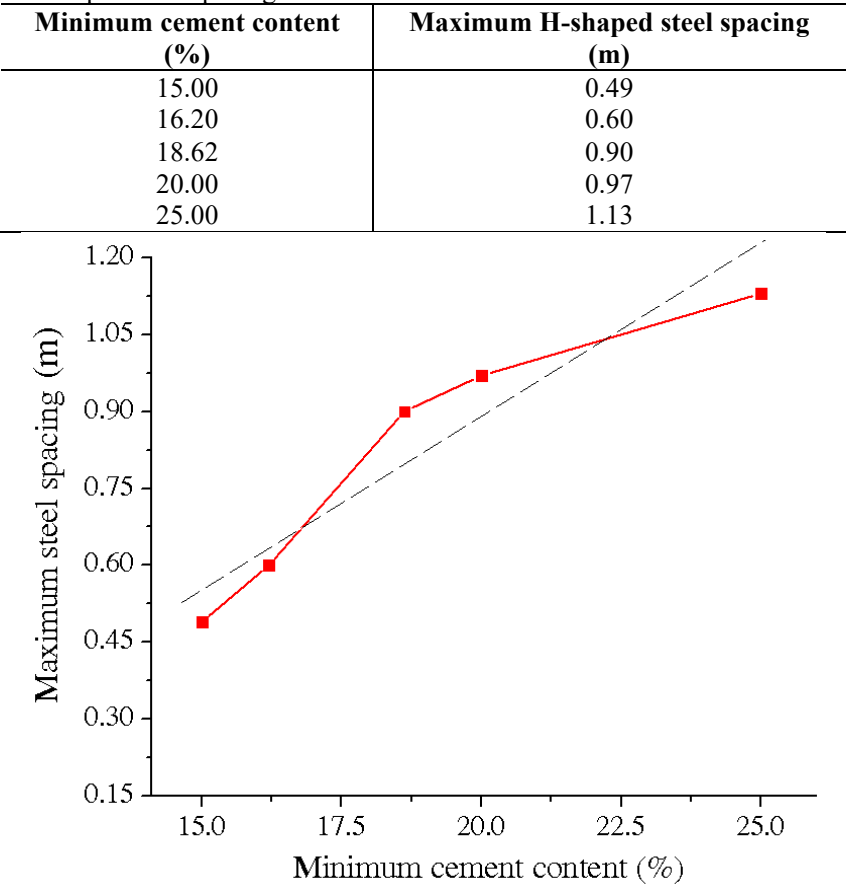

Fig. 12. The relationship between maximum steel spacing and minimum cement content.

The relationship between the mixing wall cement content $\alpha_{c}$ and the steel spacing $s$ was fitted, and that is

$s=0.0642 \alpha_{c}-0.3996$

Eq. (1) provids a reference for determining the steel spacing and the cement content in the actual engineering.

\section{Conclusions}

To ensure the stability of the foundation pit, based on the urban utility tunnel in Hangzhou, the influences of different cement content of cement-soil and the steel spacing were analyzed by using TRD excavation method, some conclusions are drawn as follows:

(1) The cement content has a significant effect on the cement-soil strength. The unconfined compressive test and the consolidation undrained shear test showes that the unconfined compressive strength and elastic modulus 
linearly increases with the cement content of cement-soil increasing in the range of $10 \%-25 \%$. The cohesion and internal friction angle of cement-soil also increases accordingly.

(2) The maximum of the horizontal displacement of $\mathrm{H}$ shaped steel and cement-soil occurres at $1 / 3$ excavation depth from the pit bottom, the cement-soil maximum horizontal bending displacement occurres in the middle position between the H-shaped steels. The tensile stress S33 is the key reason that causes the cement-soil failure mainly.

(3) With the increase of the steel spacing, the horizontal displacement of the mixing wall and the tensile stress S33 gradually increases, indicating that the steel influence on the mixing wall stiffness is greater. According to the fitted relationship between cement content and steel spacing, the steel spacing maximum with the specific cement content can be determined correspondingly, which provides a reference for the similar engineering.

These conclusions are obtained under the conditions of this study, which can provide a reference for the similar engineering, but for the new chalanging conditions, it needs to be further studied.

\section{Acknowledgements}

This work was financially supported by the National Natural Science Foundation of China (51774112), the Doctoral Fund of Henan Polytechnic University (B2015-67), and Taihang Scholars Program.

This is an Open Access article distributed under the terms of the Creative Commons Attribution License

\section{References}

1. Wu, G. M., Zhang, Z. X., Xie, Z. L., "Application of TRD method in $56.73 \mathrm{~m}$ non in situ wall forming test of Shanghai international financial center". Journal of geotechnical engineering, 35( $\left.\mathrm{S}_{2}\right)$, 2013, pp. 814-818.

2. Wang, W. D., Zou, G. E., "TRD equal thickness cement-soil mixing wall technology and engineering practice". Journal of Geotechnical Engineering, 34( $\left.\mathrm{S}_{1}\right), 2012$, pp. 628-633.

3. Russell, A. R., Chapman, M., Teh, S. H., Wiedmann, T., "Cost and embodied carbon reductions in cutter soil mix walls through fibre reinforcement". Geosynthetics International, 24(3), 2017, pp. 113.

4. Russell, D., "Diaphragm walls and cutter soil mixing". Australian Geomechanics Journal, 43(3), 2008, pp. 75-83.

5. Tan, K., Wang, W. D., Zou, G. E., "Analysis of bearing and deformation behavior of steel-reinforced cement-soil mixing wall with TRD method". Journal of Geotechnical Engineering, 37( $\left.\mathrm{S}_{2}\right)$, 2015, pp. 191-196.

6. Zheng, G., Li, Z. W., Liu, C., "Test study on flexural behavior of steel reinforced cement-soil composite". Journal of geotechnical engineering, 33(3), 2011, pp. 332-340.

7. Xie, T. W., Zuo, D. J., Wang, X. F., An, X. Y., "Study on mechanical characteristics of foundation pit retaining structure with SMW method for adjacent buildings". Journal of Chongqing Jiaotong University (Natural Science Edition), 37(3), 2018, pp. 44-50.

8. Kim, Y. S., Seo, S. G., Ko, H. W., Kim, J., "Implementation of porous material through eco-tech for deep cement-soil mixing". Marine Georesources and Geotechnology, 36(8), 2018, pp. 931-939.

9. Namikawa,T., Hiyama, S., Ando, Y., Shibata, T., "Failure behavior of cement-treated soil under triaxial tension conditions". Soils and Foundations, 57(5), 2017, pp. 815-827.
10. Suzuki, M., Fujimoto, T., Taguchi, T., "Peak and residual strength characteristics of cement-treated soil cured under different consolidation conditions". Soils and Foundations, 54(4), 2014, pp. 687-698.

11. Venkatarama Reddy, B. V., "Characteristics of cement-soil mortars". Materials and Structures/Materiaux et Constructions, 38(280), 2005, pp. 639-650.

12. Cao, Z. G., Zhang, D. W., "Study on characterization parameters of unconfined compressive strength of cement-soil". Journal of Rock Mechanics and Engineering, 34( $\left.\mathrm{S}_{1}\right), 2015$, pp. 3446-3454.

13. Ma, J. Q., Wang, Y. X., Li, H. M., Wang, G. J., "Estimation of cement-soil parameters". Architectural Science, 25(3), 2009, pp. 65-67.

14. Motohiko, M., "Construction management systems for civil engineering machinery". $R$ and D: Research and Development Kobe Steel Engineering Reports, 57(1), 2007, pp. 96-99.

15. Ruan, B., Peng, X. X., Deng, L. F., "Experimental study on shear strength parameters of cement soil". Journal of Railway Science and engineering, 13(4), 2016, pp. 662-668.

16. Zhao, X., "The relationship between unconfined compressive strength of silty clay and clay". Journal of Underground Space and Engineering, 9( $\left.\mathrm{S}_{1}\right), 2013$, pp. 1516-151.

17. Reddy, B. V. V., Gupta, A., "Strength and elastic properties of stabilized mud block masonry using cement-soil mortars". Journal of Materials in Civil Engineering, 18(3), 2006, pp. 472-476.

18. Kwon, H. M., Le, A. T., Nguyen, N. T., "Influence of soil grading on properties of compressed cement-soil". KSCE Journal of Civil Engineering, 14(6), 2010, pp. 845-853. 